\title{
Lean in healthcare from employees' perspectives
}

Erik Drotz and Bozena Poksinska

\section{Linköping University Post Print}

N.B.: When citing this work, cite the original article.

Original Publication:

Erik Drotz and Bozena Poksinska, Lean in healthcare from employees' perspectives, 2014, Journal of Health Organisation \& Management, (28), 2, 177-95.

http://dx.doi.org/10.1108/JHOM-03-2013-0066

Copyright: Emerald

http://www.emeraldinsight.com/

Postprint available at: Linköping University Electronic Press

http://urn.kb.se/resolve?urn=urn:nbn:se:liu:diva-110657 


\title{
Lean in Healthcare from Employees' Perspectives
}

\author{
Erik Drotz and Bozena Poksinska \\ Quality Technology and Management, Linköping University, Sweden
}

\begin{abstract}
Purpose - This article aims to contribute towards a deeper understanding of the new roles, responsibilities, and job characteristics of employees in Lean healthcare organizations.

Design/methodology/approach - The paper is based on three cases studies of healthcare organizations that are regarded as successful examples of Lean applications in the healthcare context. Data was collected by methods including interviews, observations, and document studies.

Findings - The implementation of Lean in healthcare settings has had a great influence on the roles, responsibilities, and job characteristics of the employees. The focus has shifted from healthcare professionals, where clinical autonomy and professional skills have been the guarding principles of patient care, to process improvement and teamwork. Different job characteristics may make it difficult to implement certain Lean practices in healthcare. Teamwork and decentralization of authority are examples of Lean practices that could be considered countercultural because of the strong professional culture and uneven power distribution, with doctors as the dominant decision makers.
\end{abstract}

Practical implications - Teamwork, value flow orientation, and company-wide involvement in CI were associated with positive effects on the organizations' working environment, staff development, and organizational performance.

Originality/value - In order to succeed with Lean healthcare, it is important to understand and recognize the differences in job characteristics between Lean manufacturing and healthcare. This paper provides insights into how Lean implementation changes the roles, responsibilities, and job characteristics of healthcare staff and the challenges and implications that may follow from this.

Keywords Lean production, job characteristics, employees' role, Lean Healthcare, work organization, challenges.

Paper type Research paper

\section{Biographical Details:}

Erik Drotz is a $\mathrm{PhD}$ student at the Division of Quality Technology and Management, Linköping University in Sweden. His research is focused on the application of Lean production in the public sector.

Bozena Poksinska is assistant professor at the Division of Quality Technology and Management, Linköping University in Sweden. Her research areas are quality management in manufacturing and service industries. Her current research focuses on quality improvement in healthcare. She also teaches quality management, Lean production, and Six Sigma at Linköping University. 


\section{Introduction}

Krafcik (1988) first mentioned the term Lean production in an attempt to explain what makes Toyota far more successful and profitable than its Western competitors. The term "lean" was used as opposite to "buffered," which was signified as the main characteristic of Western production systems. Krafcik (1988) and subsequent publications (Womack and Jones, 1996; Womack, et al., 1990) based on the IMVP (International Motor Vehicle Program) study at MIT presented the Toyota Production System as merely a development of Ford's ideas such as continuous-flow production, standardization, just-in-time and quality control. The majority of Lean production publications focused on the tools and techniques to reduce waste and to improve productivity (see e.g. Pegels, 1984; Schonberger, 1982). However, this statement does not comprise the whole truth of the success of Toyota. Several studies emphasized that the underlying principles of the Toyota Production System are continuous improvement and respect for people (e.g. Liker, 2004; Sugimori, et al., 1977). These principles are necessary conditions to achieve sustainable Lean transformation (Emiliani, 2007; Mann, 2005).

Today, Lean production is no longer exclusive to manufacturing companies. Organizations from all business sectors attempt to improve their performance using Lean production methods (Liker, 2004). Healthcare is one of the major sectors in which Lean production is being considered and adopted as an improvement program (Poksinska, 2010). Several studies may be found on how Lean production is implemented in healthcare (see e.g.Aherne, 2007; Ballé and Regnier, 2007; Furman and Caplan, 2007). Most articles include single case studies and are often published in medical journals (see e.g. Ben-Tovim, et al., 2008; Raab, et al., 2006; Spear, 2006). However, research performed in medical and management sciences has a different tradition. Medical studies usually describe the state before and after an intervention but rarely pay attention to the implementation process or consider issues such as an employee's role, behavior and engagement, work characteristics and leadership. This tradition is a major weakness in the Lean healthcare literature because those aspects are considered key to sustainable Lean implementation (e.g. Hines, et al., 2008).

The most frequently mentioned barriers to Lean implementation in healthcare are the staff's disbelief that Lean can be applied in a healthcare setting despite its origin in the automobile industry (see e.g. Fillingham, 2007; Kim, et al., 2007; Laursen, et al., 2003) and the lack of educators and consultants who have knowledge and experience of both the work organization and culture of healthcare and principles, methods and tools of Lean production (Dickson, et al., 2008; Raab, et al., 2006). The implementation of Lean in healthcare is often supported by industry consultants who have a limited understanding of the healthcare context, creating negative reactions of the healthcare staff who provide the argument: "We are not Japanese and we do not make cars" (Fillingham, 2007). Lean production was developed in an automobile industry and, not surprisingly, is perceived as countercultural for healthcare. Therefore, translating Lean principles into the healthcare language so its tools and techniques are adapted and owned by the healthcare staff is crucial (Fillingham, 2007; Poksinska, 2010). In turn, this criticality requires a greater understanding and recognition of the differences between Lean and healthcare work organization (Radnor, et al., 2012).

This article aims to contribute towards a deeper understanding of the new roles, responsibilities and job characteristics of employees in Lean healthcare organizations. First, based on a literature review, we describe the core job characteristics and related Lean practices in the Lean manufacturing context. We then identify and present the Lean practices that influenced the job characteristics in the studied healthcare organizations. Finally, we discuss the major challenges and implications of the changed job characteristics in the Lean healthcare context. 


\section{Lean Healthcare}

The first works describing Lean initiatives in healthcare were rather speculations than empirical studies. Most of them discussed the application of Lean tools and techniques into the healthcare context based on common sense and general experience (see e.g. Jacobs and Pelfrey, 1995; Spear, 2005; Whitson, 1997). Not until 2002 were research studies published that contained some evidence from Lean healthcare implementation (de Souza, 2009).

The primary reason for implementing Lean in healthcare is the increasing demands on healthcare services to provide care with high efficiency and quality (de Souza, 2009; Joosten, et al., 2009). Lean in healthcare is primarily implemented as a process improvement approach (Poksinska, 2010) and tends to focus just on tools and techniques that fail to align improvements with culture and strategy (Radnor, et al., 2012). Dahlgaard and Dahlgaard-Park (2006) stated that Lean implementation is often so focused on process improvement that it loses its perspective on people. Ballé and Regnier (2007) emphasized that the cornerstone of Lean healthcare is developing a culture in which the staff is empowered and encouraged to make improvements. The healthcare staff should focus not just on taking care of patients but also on finding improved ways to take better care of patients (Spear, 2005). However, activities such as developing a culture and empowering people for continuous improvement are often neglected (Radnor, et al., 2012).

A central concept of Lean is to understand value from the customer's perspective. From this viewpoint, the activities that do not create value should be identified and eliminated (Womack and Jones, 1996). However, several studies showed that the focus of Lean application lies on internal efficiency and cost control, and little attention is paid to defining patient value (Poksinska and Engström, 2013; Radnor, et al., 2012). The frequently mentioned problems in this respect are the ambiguity of the term "customer" in the healthcare context, conflicting goals between different stakeholders, and the lack of appropriate methods to define patient value (Endsley, et al., 2006; Hayes, et al., 2010). Focus on internal efficiency is clearly reflected by the effects of Lean healthcare as reported by different studies. The most frequently mentioned effects are "decreased overall time that patients spent in care" and "increased number of patients who can be handled" (patient throughput) (Poksinska, 2010).

Many Lean applications also neglect the sociotechnical aspects unique to healthcare (Joosten, et al., 2009). The author noted that for any lean effort to succeed, both social (human behavioral) and technical elements (technologies) are needed. However, the sociotechnical aspects of Lean thinking are a subject of debate and controversy. Lean has been criticized in a number of areas, including limited potential for creativity and innovation and creating a stressful working environment (Conti, et al., 2006; Landsbergis, et al., 1999; Parker, 2003). From a sociotechnical perspective, the application of Lean tools automatically triggers changes in job characteristics and employee wellbeing. The understanding of these interactions is crucial to realizing improvements that cannot be achieved by redesigning only the operational aspects of the care delivery process (Joosten, et al., 2009).

\section{Role of the employee in the Lean organization}

Lean is rooted in two key principles: continuous improvement and respect for people (Toyota, 2001). Sugimori et al. (1977) was the first to mention the people perspective at Toyota and emphasized that the development and utilization of workers' capabilities was as important as the removal of waste. Therefore, an important aspect is to ensure that workers can operate safely and efficiently and develop and grow as individuals. In accordance with this aspect, leaders need to delegate responsibilities and coach employees in ways that nurture their development and empower them to drive improvements (Poksinska, et al., 2013). The fundamental tool is Kaizen, a system that involves everyone in the organization - managers 
and workers alike - in a continuous endeavor to reduce waste (Liker, 2004). Liker (2004) argued for a strong interrelationship between the two principles of continuous improvement and respect for people because the improvements, to a large extent, are employee driven. Therefore, employees in Lean organizations are considered the most important resource for productivity improvement, which needs to be respected, challenged and developed (Antoni, 1996).

However, the respect for people principle was widely unrecognized and ignored by senior managers leading Lean transformations (Emiliani, 2007). For a long time, the people perspective was also omitted in Western Lean literature and began receiving more attention in recent Lean publications (Joosten, et al., 2009).

\section{Work organization in Lean manufacturing}

We describe the work organization in the Lean manufacturing context based on the research work of de Treville and Antonakis (2006). The authors performed an extensive literature review and developed a model for Lean job characteristics by extending the Hackman's and Oldham's Job Characteristics Model (JCM) (1976). Table I presents the core job characteristics in the Lean manufacturing context. The third column lists the Lean practices, which have a major impact on the identified job characteristics.

Table I. Core job characteristics in the Lean manufacturing context (based on Treville and Antonakis, 2006)

\begin{tabular}{|c|c|c|}
\hline Job characteristics & Definition & Lean practices \\
\hline Increased skill variety & $\begin{array}{l}\text { Extent to which the job requires an } \\
\text { employee to utilize multiple high- } \\
\text { level skills }\end{array}$ & $\begin{array}{l}\text { Cross training } \\
\text { Job rotation } \\
\text { Multiskilling } \\
\text { Problem-solving } \\
\text { Participation in CI }\end{array}$ \\
\hline Increased task identity & $\begin{array}{l}\text { Extent to which an employee } \\
\text { completes a whole unit of work and } \\
\text { sees the individual contribution to the } \\
\text { entire product }\end{array}$ & $\begin{array}{l}\text { Cross-training } \\
\text { Flow based layout } \\
\text { Teamwork }\end{array}$ \\
\hline Increased feedback & $\begin{array}{l}\text { Extent to which an employee receives } \\
\text { feedback on job performance }\end{array}$ & $\begin{array}{l}\text { Visual management } \\
\text { Brief daily meeting } \\
\text { Flow-based layout }\end{array}$ \\
\hline $\begin{array}{ll}\text { Increased } & \text { responsible } \\
\text { autonomy } & \end{array}$ & $\begin{array}{l}\text { Extent to which an employee has } \\
\text { responsibility and decision-making } \\
\text { authority }\end{array}$ & $\begin{array}{l}\text { Self-managed teams (decentralization of } \\
\text { authority, power sharing, participation in } \\
\text { decision making) } \\
\text { Participation in CI }\end{array}$ \\
\hline $\begin{array}{l}\text { Decreased } \\
\text { autonomy }\end{array}$ & $\begin{array}{l}\text { Extent to which an employee has } \\
\text { freedom concerning work procedures } \\
\text { and timing }\end{array}$ & $\begin{array}{l}\text { Standardized work } \\
\text { Takt time } \\
\text { Cycle time }\end{array}$ \\
\hline $\begin{array}{l}\text { Increased } \\
\text { facilitation }\end{array}$ & $\begin{array}{l}\text { Extent to which actions are directed } \\
\text { toward removing obstacles that } \\
\text { inhibit employee performance }\end{array}$ & $\begin{array}{l}\text { Coaching and supporting leadership style } \\
\text { Production levelling } \\
\text { Poka-Yoke (mistake proofing) } \\
\text { 5S (work place organisation) }\end{array}$ \\
\hline
\end{tabular}




\section{Skill variety}

Within a Lean organization, development is focused on creating multiskilled workers rather than experts within a specific profession for a high degree of job rotation (Pil and Fujimoto, 2007). Monden (1983) suggested several benefits of multiskilled workers and job rotation, such as decreased muscular fatigue, more even workload, and increased knowledge utilization. A learning aspect exists because every employee gains experience from every part of the process, which generates more improvement ideas and simplifies the diffusion of new ways of working (Monden, 1983). However, some empirical studies showed that job rotation may increase the stress level among employees (Conti, et al., 2006).

Employees also use more of their skills and talents in improvement and problem-solving activities. In Lean production, problems are seen as opportunities for improvement (Liker, 2004). An expression of this is the Andon-sign, which the staff uses to highlight problems instead of hiding them (Adler, et al., 1999). When a problem is detected, finding its root cause is emphasized to work proactively to prevent similar problems in the future (MacDuffie, 1997). Lean critics state that front-line workers have limited opportunities to learn and engage in problem solving (Fucini and Fucini, 1990).

\section{Task identity}

Multiskilling and cross training also contributes to increased task identity. Workers learn the different parts of the process and understand more how their work contributes to the final product (de Treville and Antonakis, 2006). One of the core concepts of Lean production is value flow, which implies identifying and understanding all of the activities required to make a product (Womack and Jones, 1996). The essential steps needed to get the job done should be organized into a continuous flow with no interruptions, no batches and inventories, and no queues and wasted motions (Ohno, 1988). The functionally related assembly tasks are assigned to self-managed teams, which increases the task identity (Pil and Fujimoto, 2007). In a continuous flow layout, workers perform much more value-adding work and can more easily see the results of this work, which gives them a sense of accomplishment and satisfaction from the work (Liker, 2004). Task identity also refers to the completeness of a work task, which means doing the task from beginning to end. In this respect, Lean production with short cycle times and highly repetitive work is rather associated with low task identity (de Treville and Antonakis, 2006).

\section{Feedback}

The Lean methods that enhance constant feedback to employees are visual control and daily management (Mann, 2005). Visual control is a technique for creating an environment rich in instant and visually stimulating information. Simple visual tools such as boards, displays, color-coding and labels are used to provide timely feedback on process performance and to clarify each day's goals. Brief daily meetings support two-way communication with employees and to ensure follow-up on task assignments. The meetings usually have fixed times and durations and follow a standardized agenda that often includes planning daily activities, checking the conditions to meet the day's demands, reviewing objectives, and discussing different problems faced in daily work (Poksinska, et al., 2013). Feedback is also encouraged through a flow-based layout, which makes it easier for workers to communicate information upstream (de Treville and Antonakis, 2006).

\section{Responsible autonomy}

Teamwork is the fundamental work unit in Lean organizations (Liker, 2004). Teams are responsible for completing daily operations and continually improving their performance. Liker and Hoseus (2010) argued that mutual trust within working teams as well as between team members and managers is a cornerstone in a Lean environment. The goal is to create a culture in which mutual growth instead of individual benefits is enhanced, and in which an 
individual team member gives up something to reach a team goal. To a large extent, Eiji Toyoda confirmed this view (Shimokawa and Fujimoto, 2009), stating that a significant difference between the improvement systems at Ford Motor Company and Toyota is that Ford focuses on rewarding suggestions from individuals whereas Toyota promotes team participation.

The decision making within a lean organization is largely built on decentralization (Liker and Convis, 2011). Therefore, teams are responsible for managing daily activities and have the authority to make decisions on their own standards. Managerial responsibility is passed to team members, which is one way to realize participation, empowerment, and the utilization of employee skills (Poksinska, et al., 2013). However, empirical studies showing very limited or temporary increases in employee empowerment at Lean organizations creates questions about these statements (Landsbergis, et al., 1999).

\section{Choice autonomy}

A Lean work organization is characterized on one side by increased responsibility and autonomy arising from decentralization of authority, power sharing, and participation in decision making. On the other side, such an organization represents decreased choice autonomy because of limited freedom concerning working procedures and timing (de Treville and Antonakis, 2006). In this respect, the important techniques are standardized work and takted production. Standardization of working procedures is well-known as an important part of Lean philosophy, both to control safety, quality, and efficiency (Monden, 1983) and as a basis for continuous improvement (Ohno, 1988). This high degree of standardization makes it possible to keep a takted production with a defined and preferable short cycle time (Monden, 1983). Standardized work and short cycle times are considered to be factors that cause negative effects on the work environment such as increased job depression, reduced organizational commitment, and role breadth self-efficacy (refers to employees' confidence to carry out a range of proactive, integrative, and interpersonal tasks) (Parker, 2003).

\section{Work facilitation}

According to de Treville and Antonakis (2006) Hackman's and Oldham's Job Characteristics Model has its limitations in describing Lean job characteristics and needs to be extended with work facilitation. This job dimension refers to "to actions centered on removing obstacles that inhibit worker performance and on the provision of resources that are instrumental for the achievement of worker goals" (de Treville and Antonakis, 2006).

The Lean organizational structure is often illustrated using an inverted pyramid, with managers at the base and employees at the top. This inverted pyramid aims to signify that the primary role of managers is to serve and meet the needs of front-line workers (Liker and Convis, 2011). The managers' principal tasks are to coach and support workers and to create a learning and facilitative work environment (Poksinska, et al., 2013).

Several Lean tools such as Poka-Yoke, 5S, and visual control aim to facilitate and enhance employees in carrying out work. Visual information and instructions are placed in plain sight of employees to simplify the work and make it easy to recognize abnormalities. Poka-Yoke helps to prevent or correct mistakes, and $5 \mathrm{~S}$ creates a safe, organized, and clean workplace in which problems are easily visible (Liker, 2004).

\section{Methodology}

The empirical evidence presented in this paper was collected in three healthcare organizations. For the purpose of the paper, the case organizations were assigned names that reflect their primary characteristic associated with the Lean implementation approach. 
The first case organization, named Lean Culture, is a care center that provides primary healthcare services for a municipality of approximately 2,500 citizens. Lean Culture has approximately 25 employees, including doctors, nurses, dieticians, and administrative staff. Lean Culture had previously been in a somewhat troublesome situation, with many employees experiencing high levels of stress. Lean was initiated to improve the work environment. From the beginning, the implementation focused on building a culture with empowered employees that drive the improvement work.

The second case organization, named Lean Leadership, is a physiology unit at a hospital that investigates the heart, blood vessels, and lungs, both for in-house patients and outpatients. The unit has approximately 20 employees, a majority of whom are biomedical technicians. The unit, which has a long tradition of improvement work and was interested in further developing their working, had no special reason to start with Lean. The initiative came from the head of the division, who is the primary driving force behind the Lean work.

The third case organization, named Lean Projects, is a care center providing primary healthcare services to citizens of one of the Stockholm's municipalities. In recent years, privately owned care centers have been established in the municipality, putting this care center in a competitive situation. Lean Projects needed to reduce waiting times and improve the quality of the care provided to ensure its future survival. In this case, Lean work is primarily executed through discrete projects focusing on solving different problems of the health center.

The case methodology was chosen because it allows gaining a detailed understanding of the concepts under investigation and provides the possibility of studying phenomena in a real-life context (Yin, 2003). The empirical evidence was collected through interviews, observations, participation in meetings, and studies of company data and documentation.

The interviews were semi-structured and took approximately one to two hours depending on the interviewee. The interview questions focused on four main areas: how Lean production is defined and perceived by the organization; how Lean production was implemented; how the improvement work is organized; and how the roles and responsibilities of employees changed after Lean production was implemented, and all interviews were taped and transcribed. The interview material was analyzed using content analysis to seek pattern-matching between categories that emerged from the data (empirically based patterns) and the study's theoretical assumptions (predicted patterns in the form of job characteristic dimensions) (Merriam, 1998). For more details on the interviews, see Table II.

Table II. Interviews performed at case organizations

\begin{tabular}{l|l|r}
\hline & Interviews & Total \\
\hline Lean Culture & 1 head (doctor), 2 doctors, 3 nurses & 6 \\
\hline Lean Leadership & $\begin{array}{l}1 \text { head (doctor), 2 doctors, 1 assistant nurse, 4 biomedical technicians, } \\
\text { secretaries }\end{array}$ & 10 \\
\hline Lean Projects & 1 head (physiotherapist), 4 doctors, 2 nurses, 1 administrator & 8 \\
\hline
\end{tabular}

Participant observations were made at several meetings using structured field notes (DeWalt and DeWalt, 2002). Finally, several company documents such as strategies, documented procedures, and implementation plans were analyzed using qualitative content analysis (Merriam, 1998). The data collection methods were combined to offer multiple data sources. 


\section{Findings}

Based on Table I, we identified the following 10 Lean practices that had been implemented in the three healthcare organizations studied: continuous improvement, problem solving, flow orientation, self-managed teams, visual control, brief daily meetings, standardized work, coaching and supporting leadership style, and 5S. Since the flow-based layout was comprehensively adapted to the healthcare context, its name was changed to flow orientation. Some of the practices, such as self-managed teams and visual control, were implemented to a very limited extent. The Lean practices that were not implemented in the studied organizations were: cross-training, job rotation, multiskilling, takt time, cycle time, Poka Yoke, and production leveling.

\section{Continuous improvement and problem solving}

All three case organizations introduced processes and routines that engaged employees in continuous improvement. The departure point for CI at Lean Leadership and Lean Projects was to capture daily irritations and problems. The employees were requested to write down every disruption and problem they experienced during the working day and post it on a white board. Weekly meetings were initiated to review the Post-its and discuss how the problems could be solved. At Lean Projects, this process resulted in many parallel projects and the employees stated that CI created more stress at work:

A lot of parallel projects are running that affect the work situation. It is expected that we should participate in a lot of projects (...) I think employees get very fragmented, actually (Doctor at Lean Projects).

After some time, CI at Lean Projects reached a standstill. At the time the study was carried out, the whiteboard was empty and improvement projects were initiated and coordinated by the management board.

At Lean Leadership, the whiteboard practice was a way to create motivation and engagement for CI.

We discussed the problems weekly at the whiteboard. It was surprising to see that we all experienced the same problems, but had just accepted them before. It was so motivating that finally someone listened to us and we tried to solve the problems... (Nurse at Lean Leadership)

The focus at Lean Leadership was not to realize as many improvements as possible, but to develop supporting structure and enabling culture for CI. Small improvements were realized by giving responsibility to one or two employees, while larger improvements were passed to improvement teams that were established around core processes. Lean Culture also adopted the improvement approach for establishing improvements teams around core processes; there, the first goal for CI was to improve the stressful wok situation. This goal created a strong commitment for CI.

The supporting structures for CI at Lean Culture and Lean Leadership were the weekly improvement meetings. The meetings were used to create engagement and coordinate the improvement work; that is, report on-going initiatives, bring up new ideas or problems, discuss possible solutions, and plan who will realize the improvements and how. Regular and frequent meetings, as well as allocating time and resources, were the important factors in ensuring that $\mathrm{CI}$ becomes an integrated part of the daily work.

Employees at Lean Culture and Lean Leadership talked about their changed roles in a Lean organization. Apart from the roles of taking care of patients (doctors and nurses) or supporting the healthcare staff (administrative staff), they received an additional new role that implied 
improvements in the care delivery processes. Most employees took an active role in CI by detecting problems and waste and suggesting and implementing improvements.

\section{Flow orientation}

At the point of Lean initiation, the flow orientation at the case study organizations was very weak. Every employee was focused on her/his own work and there was no thinking about how the parts were connected and how the value is created for the patient. In all three cases, Value Stream Mapping (VSM) was used to identify the core processes of the organizations. Some value streams were mapped from the patient's perspective and others from the healthcare staff perspective. VSM from the patient perspective implied the analysis of patient flow through each stage of the process. VSM from the healthcare staff perspective considered other healthcare providers or healthcare staff themselves as customers and mapped staff activities.

At Lean Projects, VSM was primarily considered as a tool for realizing improvements. For example, the value flow of reception and doctor visits was mapped. A team representing various healthcare professionals mapped what happens from the moment the patient calls to make an appointment until she/he receives the required care. The next step was to identify the different time wasters. When the improvements were realized, the flow orientation was basically abandoned.

Lean Culture and Lean Leadership adopted a different approach. VSM and flow orientation were the primary methods used to reorganize the work and build supporting structures for CI. VSM was a way of visualizing the processes and creating a common view of the patient flows or activities flows for all employees. When VSM was completed, a cross-profession team responsible for planning, managing, and improvement activities was allocated to the value stream. The allocation of cross-profession teams to value streams was a permanent structure of the new Lean organization. It is important to note that only a few (three or four) selected value streams were organized in this way. In some cases, flow orientation was temporary and VSM was used in the same way as at Lean Projects.

One of the frequently mentioned results of flow orientation was a focus on facilitating the work for each other and making it as smooth as possible for all professions involved.

I think very often now what the next step in the flow is. I think how I can simplify the work for the next person in the process ... I reflect on whether I will create a problem for the next step of the process... It doesn't matter who is the next in the process. We have to help each other if we want the work to flow smoothly and not cause stress (Doctor at Lean Culture).

\section{Self-managed teams}

Lean implementation brought a change in focus from individual work to teamwork. In all three cases, temporary improvement teams were created to work with a specific improvement idea. The improvement activities were often performed by cross-profession teams that included employees from different professional groups. Apart from the temporary teams for realizing improvements, more daily work was also performed in teams. At Lean Culture and Lean Leadership, cross-profession teams were established with the responsibility of managing and improving various patient flows. At Lean Leadership, some individual work was reorganized into teamwork. Various professions that had previously met the patient separately, now met the patient as a team. The team orientation also increased at Lean Projects since cross-profession teams were allocated to more long-term projects with the aim of improving the care of certain patient groups, such as diabetes patients.

Before the introduction of Lean, there was a clear hierarchy by which doctors had far more influence and power than other professions. This led to distinct boundaries between different professional groups and minimal cooperation between them. Teamwork on improvements 
weakened the hierarchical structure, since every member of the team had the same position and role and was expected to contribute to improvements. At both Lean Culture and Lean Leadership, several employees described a culture built on cooperation for mutual benefit.

We are helping each other in a new way. Doctors are sometimes asking us [assistant nurses] for help and advice (Nurse at Lean Culture).

Consequently, some tasks have been transferred between different professional groups and between managers and employees, which has increased the cooperation and made the work more efficient overall. An example at Lean Culture was that some doctors started to do the record-keeping themselves, which was previously done by administrative staff. Another example is that one of the process improvement teams was led by a doctor's secretary who, in that position, acted as a process leader for the doctors in her team. At Lean Culture, several employees also indicated that the teamwork led to decreased stress levels:

The stress level has decreased since we work in teams. We can talk to each other; solve a lot of minor issues that are not on the agenda and then the stress level decreases (Employee at Lean Culture).

\section{Visual control and brief daily meetings}

In all three case organizations some aspects of visual control was introduced. The most obvious example was visualization of improvement work at Lean Leadership and Lean Culture. The improvement boards displayed the status of the different improvements with magnetic dots in traffic-light colors and indicated the responsible and planned actions. The improvement ideas also included space for submitting improvement ideas.

The case organizations also introduced visual control of organizational objectives. Whiteboards showing the organizations' vision, goals, values, and important performance measures were used. At Lean Leadership, for example, the whiteboard displayed information such as patient throughput, waiting times, time spent on every patient from referral to providing test results, patient safety and satisfaction indicators, employee stress, and financial status. The indicators were updated monthly (such as waiting times) or weekly (such as patient throughput).

No means of visual control were used to manage the daily work. The healthcare staff did not receive any feedback on the status of the work during the working day, which is the case in Lean manufacturing companies. Several respondents stated that discussions were held on metrics that provide daily and timely feedback on process performance, but these were considered difficult to implement in the healthcare context. Lean Culture raised concerns about the patient safety, since the use of handwritten notes or Post-its did not seem to fulfill the safety requirements.

Other examples of visual control were diverse instructions displayed in storage, printers, and nurses' rooms, which aimed to simplify the work and minimize the time used on different tasks.

Lean Culture and Lean Leadership also introduced brief daily morning meetings. The purpose of these meetings was to increase communication and to involve employees in planning and coordinating the daily operations, decision making, problem solving, and goal setting. This provided the healthcare staff with greater insights into the organization and they felt more ownership of the work situation. The employees also found that they became more involved in decision making. This shift led to an increased authority and empowerment, and a sense of self-control in the daily work.

We are involved in all decision making and we are allowed to influence the operations greatly (Biomedical technician at Lean Leadership). 


\section{Standardized work}

Standardized work is an important part of Lean work. All of the case study organizations aimed to standardize as much as possible. Different processes and procedures were discussed and common standards were set to simplify the work and make the time necessary to perform a task more predictable and constant. There were slightly different approaches to standardized work at care center cases and the physiology cases. At care centers, the focus of standardization was the administrative routines and processes, which did not imply direct patient contact. The patient-doctor meetings were not a subject of discussion and standardized work was not introduced in this aspect of care. At the physiology clinic, on the other hand, the examination procedures were also subject to standardized work. The various professional groups discussed and agreed on common procedures for performing the examinations. The difference may follow from the nature of the healthcare processes. The care centers have a wide range of patients, which require different diagnosis procedures. The physiology unit provided more specific care services to several limited groups of patients.

\section{Coaching and supporting leadership style}

The heads of the case organizations indicated that, for them, the Lean implementation implied a change in managerial tasks. In short, the change was about shifting attention from processes to people. An important task was to develop the motivation and engagement for change and CI. The managers paid more attention to building relations with employees and developing individuals and teams. The head of Lean Culture described that he attempted to be more visible in his daily work. He started to walk around the care center just to chat with employees and socialized more during coffee breaks. The heads of Lean Leadership and Lean Projects emphasized that it is important to lead employees not by power of position, but by personal influence and concern for individual needs and development. To increase the participation in work, the managers started to gradually pass the responsibility for the daily management of activities to individual employees and teams. They focused on empowering employees to take control of their work process and involving them in improvement activities.

\section{$5 S$}

All three case organizations implemented some $5 \mathrm{~S}$ activities. In most of the cases, it was a one-time activity and not a permanent routine with regular audits. Employees agreed about how they would like to have certain things placed or organized, and implemented the changes without paying attention to how the standards would be maintained. An example of all five steps (sorting, setting in order, systematic cleaning, standardizing, and sustaining) being implemented was the introduction of standardized examination trolleys at Lean Projects. Before the implementation of Lean, each doctor has his or her own examination room with different equipment and medical accessories. This was not optimal since there were more doctors than examination rooms (several doctors worked part-time and the care center was used to educate medical students). There were often discussions about who should take which room. As result of Lean work, a standardized examination trolley was introduced. The doctors agreed on what items should be included and how they should be organized on the trolley. An external person was hired, who replenished the trolleys every evening according to the standard. The doctors no longer had assigned rooms and instead used any available room. This improvement was used as an example of extensive time and cost savings.

\section{Discussion}

This section discusses the major challenges and implications of the changed job characteristics in the Lean healthcare context. 


\section{Skill variety}

Our results have shown that the Lean implementation has introduced a new role for healthcare staff, which is about involvement in problem solving and improvement activities. This leads to increased cooperation between different professional groups and improved utilization of multiple high-level skills.

Tucker and Edmondson (2003) found that problem solving and CI is not widely practiced in healthcare organizations today. When healthcare staff experience an interruption, problem, or other distraction in daily routine, they work around the problem without bringing attention to it. The authors also suggest that the physical presence of patients when performing the work takes attention away from the problem itself, and instead places the focus on the current patient's comfort and safety. It is a dedicated and highly skilled professional staff, which is supposed to compensate for any operational failures that might occur during the care delivery process (Tucker and Edmondson, 2003). In fact, this leads to a system in which problems are hidden rather than seen as a possibility for improvement (Mann, 2005). The implementation of Lean makes a radical change in this respect, which might be beneficial both for healthcare professionals and for patients.

When implementing CI in healthcare, attention should be given to allocating time and resources and creating supporting structures with increased responsibilities and authority for employees, two-way communication, teamwork, and regular and frequent improvement meetings. If CI is integrated into the daily work, employees will experience it as positive and developmental. The case of Lean Projects shows that if CI is executed in many parallel projects, it could increase stress and destroy the engagement.

Job rotation and multiskilling were Lean practices, which increase skill variety, but were not used in case organizations. Because healthcare is a very complex field, with a high variability of tasks and high knowledge intensity, job rotation and multiskilling are unsuitable for application in this context.

\section{Task identity}

The flow orientation in Lean manufacturing is positively associated with increased task identity (de Treville and Antonakis, 2006). However, the flow orientation in healthcare is weak (Hellström, et al., 2010). Flow orientation and teamwork have definitely contributed to increased task identity since the staff received better insights into how their work contributes to the value stream and what other professional groups do. However, in healthcare there is often a limited possibility for staff to experience the completeness of the work task. The complexity of care processes and the knowledge intensive tasks often imply that healthcare professionals work in silos and that there is a lack of cooperation between healthcare units. Many patient flows involve care activities at several healthcare units and, in many cases, it is difficult to say which unit is the owner and should take responsibility for improving the entire flow. It is often necessary to extend Lean beyond the borders of a single healthcare unit. Creation of cross-organizational teams responsible for the entire patient flow would further increase the task identity and will offer new opportunities to provide more efficient care.

It is important to indicate that the team organization in the studied Lean healthcare cases was different to what the Lean literature describes as team organization. In healthcare, there were many different constellations of teams: improvement teams, teams temporarily assigned to projects, process teams, and teams responsible for treating certain patients groups. One healthcare professional was not assigned to one team, but could work during the week in many different teams. While this certainly contributes to increased task identity, it could be experienced as stressful. 


\section{Feedback}

The implementation of visual control and brief daily meetings increased feedback on work performance. The visualization of performance measures improved the understanding of the organizational goals and increased commitment for CI. However, it seems that realization of the full potential of visual control and daily management is limited by the nature of care processes. The case organizations considered it difficult to implement daily instant feedback metrics on process performance. There are known applications of visual control to daily management of patient flow (Graban, 2008; Xiao, et al., 2007). Some examples of metrics used in visual control of patient flow are: patient status, discharge times, necessary checks, and handoffs. Visualization of patient flow provides several benefits; for example, doctors may reduce delays between the moment at which information becomes available and the time when decisions are carried out, or nurses can see how they can best leverage resources and coordinate work (Graban, 2008). While the benefits of visual management in healthcare appear obvious, there are also some concerns. Do the traditional whiteboards, which often are used in visual control, fulfill the requirements for patient safety? If information should be readable and accessible to everyone, is it of sufficient quality to ensure correct decisions and avoid mistakes? Can unauthorized individuals access information?

\section{Responsible autonomy}

In Lean manufacturing, responsible autonomy is increased through self-managed teams, decentralization of authority, power sharing, and participation in decision making. However, teamwork is not easy to implement in the healthcare context because of the power structure and relationships among the staff. Employees have a very strong sense of identity with the professional groups. The culture is still very hierarchical, with doctors as the dominant decision makers. Knowledge contributions are valued differently and employees from other groups are seldom encouraged to give their opinion when decisions are made (Tucker and Edmondson, 2003). These aspects are a barrier to team-based organization, which in Lean is the primary operational unit for managing and improving processes (Ballé and Regnier, 2007; Laursen, et al., 2003).

\section{Choice autonomy}

Standardization is associated with low choice autonomy since the ability to decide how to perform tasks in the daily work is reduced. Doctors are highly trained individuals and have been trained to act with autonomy. Standardization has a negative connotation in healthcare and can cause negative reactions among doctors (Timmermans and Berg, 2003). The standardization of work processes makes the system much less dependent on individuals. It also implies changes in the role of employees, from highly skilled individuals who act on their own decisions in order to treat patients to members of a collective who follow more standardized procedures. There is also a difficulty and resistance to overly far-reaching standardization of tasks that include contact with the patient, since all patients have different needs. For this reason, takt time and cycle are rarely implemented in the healthcare context. However, many administrative processes and physical workplaces could be standardized, which can lead to more effective processes.

\section{Work facilitation}

Not all Lean practices related to work facilitation were implemented in the healthcare context. Production leveling has a limited application to the healthcare context and Poka Yoke, although it does have the potential for patient safety, was not used by the case organizations. 5S was implemented and there do not seem to be any special challenges related to this tool. Finally, although a coaching and supporting leadership style was implemented to some extent, there are significant differences in this respect between the manufacturing and healthcare contexts. Healthcare leaders are usually skilled in their own fields but are not experts in 
people management and they have often limited knowledge about how to motivate, coach, and engage employees. Healthcare leaders frequently work in clinical practice and only manage healthcare units part-time. They have often limited opportunities and interest in acting as facilitators and coaches to healthcare staff. Professional knowledge is also a barrier in this respect.

\section{Conclusions}

Although Lean production has been widely implemented in the healthcare sector, little attention has been paid to the implications of Lean production on job characteristics of healthcare professionals. By researching and analyzing how Lean production influences the roles, responsibilities, and job characteristics of healthcare professional, we were able to provide several important theoretical and practical implications that are significant for Lean implementation in the healthcare context.

\section{Theoretical implications}

The implementation of Lean production does not occur in a vacuum, but implies an active translation and adaptation process of the management ideas into a context of other ideas, actors, traditions, and practices (Sahlin and Wedlin, 2008). Some of the Lean practices may be easily adapted into the healthcare context, whereas others may be associated with significant challenges or barriers. This often occurs when there are significant differences between the transferred management ideas and the context of the involved organization. The present study identified the following Lean practices that were associated with challenges due to different job characteristics in healthcare:

- Visual control and brief daily meetings have increased feedback on job performance. However, it remains challenging to implement daily instant feedback metrics on patient flows. This is due to the nature of healthcare processes and risks related to patient safety.

- Self-managed teams, decentralization of authority, power sharing, and participation in decision making have increased responsible autonomy. The challenges related to this aspect are the strong professional culture and uneven power distribution, with doctors as the dominant decision makers.

- Increased standardization has had a negative influence on choice autonomy. This Lean practice is difficult to implement in healthcare since it is considered to be incorrect due to the unique needs of each patient and a tradition of acting based on professional autonomy.

- Lean leads to increased work facilitation, but Lean practices related to this job dimension have limited application to healthcare or have only been partially implemented. One of the challenges is the role of healthcare leaders, who often have limited experience and limited interest in applying coaching and supporting the leadership style.

\section{Practical implications}

The present study has shown that the implementation of Lean in three healthcare organizations has had a great influence on the roles, responsibilities, and job characteristics of the employees. These changes have implied a positive effect on organizations' working environment, staff development, and organizational performance. Three Lean practices were specifically associated with these positive effects: teamwork, value flow orientation, and everybody's involvement in CI.

The cross-profession teamwork decreased the hierarchical structure and boundaries between professional groups, which fostered cooperation and a positive improvement climate at work. 
The traditional focus on healthcare professionals, where the clinical autonomy and professional skills have been the guarding principles of patient care, has shifted to a focus on process improvement and team-work.

Flow orientation and teamwork have contributed to increased task identity. Staff received better insights into the patient flow and how their work contributes to the value flow. Flow orientation and teamwork has also increased understanding about the work of other professional groups and led to greater utilization of knowledge. Flow orientation is weak in healthcare, which means there is great potential for further improvements in this area.

The implementation of Lean production implied that employees took increased responsibility for improving and managing daily activities. The new role and participation in CI and problem solving has increased skill variety. Employees appreciated the increased responsibilities and autonomy to perform a wider variety of tasks, and felt respected and valued. Since CI and problem solving are not widely practiced in healthcare, Lean can make a significant contribution to healthcare improvement, but attention should be directed towards the creation of supporting structures that integrate CI into daily work.

In respect to the above-mentioned positive effects, we suggest that Lean implementation in healthcare should promote teamwork, value flow orientation, and CI in order to build motivation and strengthen commitment to Lean among healthcare staff.

\section{References}

Adler, P. S., Goldoftas, B., and Levine, D. I. (1999), "Flexibility versus efficiency? A case study of model changeovers in the Toyota production system", Organization Science, Vol. 10 No. 1, pp. 43-68.

Aherne, J. (2007), "Think lean", Nursing Management, Vol. 13 No. 10, pp. 13-15.

Antoni, C. (1996), "Lean production in Europe: A matter of technical adjustment or cultural change?", Applied Psychology, Vol. 45 No. 2, pp. 139-142.

Ballé, M. and Regnier, A. (2007), "Lean as a learning system in a hospital ward", Leadership in Health Services, Vol. 20 No. 1, pp. 33-41.

Ben-Tovim, D., Bassham, J., Bennett, D., Dougherty, M., Martin, M., O'Neill, S., Sincock, J., and Szwarcbord, M. (2008), "Redesigning care at the Flinders Medical Centre: Clinical process redesign using 'lean thinking'", Medical Journal of Australia, Vol. 188 No. 6, pp. 27-31.

Conti, R., Angelis, J., Cooper, C., Faragher, B., and Gill, C. (2006), "The effects of lean production on worker job stress", International Journal of Operations\&Production Management, Vol. 26 No. 9, pp. 1013-1038.

Dahlgaard, J. J. and Dahlgaard-Park, S. M. (2006), "Lean production, six sigma quality, TQM and company culture", The TQM Magazine, Vol. 18 No. 3, pp. 263-281.

de Souza, L. (2009), "Trends and approaches in lean healthcare", Leadership in Health Services, Vol. 22 No. 2, pp. 121-139.

de Treville, S. and Antonakis, J. (2006), "Could lean production job design be intrinsically motivating? Contextual, configurational, and levels-of-analysis issues", Journal of Operations Management, Vol. 24 No. 2, pp. 99-123.

DeWalt, K. M. and DeWalt, B. R. (2002), Participant Observation: A Guide for Fieldworkers, AltaMira Press, Plymouth.

Dickson, E. W., Singh, S., Cheung, D. S., Wyatt, C. C., and Nugent, A. S. (2008), "Application of Lean Manufacturing Techniques in the Emergency Department", Journal of Emergency Medicine, Vol. 37 No. 2, pp. 177-182.

Emiliani, B. (2007), Real lean: understanding the lean management system, The Center for Lean Business Management, LLC, Wethersfield. 
Endsley, S., Magill, M. K., and Godfrey, M. M. (2006), "Creating a lean practice", Family Practice Management, Vol. 13 No. 4, pp. 34-38.

Fillingham, D. (2007), "Can lean save lives?", Leadership in Health Services, Vol. 20 No. 4, pp. 231-241.

Fucini, J. J. and Fucini, S. (1990), Working for the Japanese: Inside Mazda's American auto plant, Free Press, New York.

Furman, C. and Caplan, R. (2007), "Applying the Toyota Production System: using a patient safety alert system to reduce error", The Joint Commission Journal on Quality and Patient Safety, Vol. 33 No. 7, pp. 376-386.

Graban, M. (2008), Lean Hospitals: Improving Quality, Patient Safety, and Employee Satisfaction, Productivity Press, Boca Raton.

Hackman, J. R. and Oldham, G. R. (1976), "Motivation through the design of work: Test of a theory", Organizational Behavior and Human Performance, Vol. 16 No. 2, pp. 250279.

Hayes, K., Reed, N., and Fitzgerald, J. (2010), "Who are your Lean Health customers?: Identifying influential Lean customers in health cervices: Current practice and insights from stakeholder analysis", Asia Pacific Journal of Health Management, Vol. 5 No. 1, p. 53.

Hellström, A., Lifvergren, S., and Quist, J. (2010), "Process management in healthcare: investigating why it's easier said than done", Journal of Manufacturing Technology Management, Vol. 21 No. 4, pp. 499-511.

Hines, P., Found, P., Griffiths, G., and Harrison, R. (2008), "Staying Lean: Thriving not just surviving", Lean Enterprise Research Centre, Cardiff.

Jacobs, S. and Pelfrey, S. (1995), "Applying just-in-time philosophy to healthcare", Journal of Nursing Administration, Vol. 25 No. 1, pp. 47-52.

Joosten, T., Bongers, I., and Janssen, R. (2009), "Application of lean thinking to health care: Issues and observations", International Journal for Quality in Health Care, Vol. 21 No. 5, pp. 341-347.

Kim, C. S., Hayman, J. A., Billi, J. E., Lash, K., and Lawrence, T. S. (2007), "The application of Lean thinking to the care of patients with bone and brain metastasis with radiation therapy", Journal of Oncology Practice, Vol. 3 No. 4, pp. 189-193.

Krafcik, J. (1988), "Triumph of the Lean Production System", Sloan Management Review, Vol. 30 No. 1, pp. 41-52.

Landsbergis, P., Cahill, J., and Schnall, P. (1999), "The impact of lean production and related new systems of work organization on worker health", Journal of Occupational Health Psychology, Vol. 4 No. 2, pp. 108-130.

Laursen, M., Gertsen, F., and Johansen, J. (2003), "Applying lean thinking in hospitalsexploring implementation difficulties", in 3rd International Conference on the Management of Healthcare and Medical Technology, Warwick, pp. 1-15.

Liker, J. (2004), The Toyota Way: 14 Management Principles from the World's Greatest Manufacturer, McGraw-Hill, New York.

Liker, J. and Convis, G. L. (2011), The Toyota Way to Lean Leadership: Achieving and Sustaining Excellence Through Leadership Development, McGraw-Hill, New York.

Liker, J. K. and Hoseus, M. (2010), "Human Resource development in Toyota culture", International Journal of Human Resources Development and Management, Vol. 10 No. 1, pp. 34-50.

MacDuffie, J. P. (1997), "The road to 'root cause': Shop-floor problem-solving at three auto assembly plants", Management Science, Vol. 43 No. 4, pp. 479-502.

Mann, D. (2005), Creating a Lean Culture: Tools To Sustain Lean Conversions, Productivity Press, Portland. 
Merriam, S. B. (1998), Qualitative Research and Case Study Applications in Education, Rev. and expanded edition ed., Jossey-Bass, San Francisco.

Monden, Y. (1983), Toyota Production System: Practical Approach to Production Management, Engineering \& Management Press, Atlanta.

Ohno, T. (1988), Toyota Production System: Beyond Large-Scale Production, Productivity Press, Portland.

Parker, S. (2003), "Longitudinal effects of lean production on employee outcomes and the mediating role of work characteristics", Journal of Applied Psychology, Vol. 88 No. 4, pp. 620-634.

Pegels, C. C. (1984), "The Toyota production system-lessons for American management", International Journal of Operations \& Production Management, Vol. 4 No. 1, pp. 3-11.

Pil, F. K. and Fujimoto, T. (2007), "Lean and reflective production: the dynamic nature of production models", International Journal of Production Research, Vol. 45 No. 16, pp. 3741-3761.

Poksinska, B. (2010), "The current state of Lean implementation in healthcare - literature review", Quality Management in Health Care, Vol. 19 No. 4, pp. 319-329.

Poksinska, B. and Engström, J. (2013), "Value in Lean Healthcare - a critical appraisal from a service perspective ", presented at the 13th International Research Symposium on Service Excellence in Management, Karlstad, Sweden.

Poksinska, B., Swartling, D., and Drotz, E. (2013), "The daily work of Lean leaders - lessons from manufacturing and healthcare", Total Quality Management \& Business Excellence, Vol. 24 No. 7-8, pp. 886-898.

Raab, S. S., Andrew-JaJa, C., Condel, J. L., and Dabbs, D. J. (2006), "Improving Papanicolaou test quality and reducing medical errors by using Toyota production system methods", American Journal of Obstetrics and Gynecology, Vol. 194 No. 1, pp. 57-64.

Radnor, Z. J., Holweg, M., and Waring, J. (2012), "Lean in healthcare: The unfilled promise?", Social Science \& Medicine, Vol. 74 No. 3, pp. 364-371.

Sahlin, K. and Wedlin, L. (2008), "Circulating ideas: Imitation, translation and editing", in The Sage handbook of organizational institutionalism, Greenwood, R., et al., Eds., Sage Publications, London, pp. 218-242.

Schonberger, R. (1982), "Some observations on the advantages and implementation issues of just-in-time production systems", Journal of Operations Management, Vol. 3 No. 1, pp. 1-11.

Shimokawa, K. and Fujimoto, T. (2009), The Birth of Lean: Conversations with Taiichi Ohno, Eiji Toyoda, and Other Figures who Shaped Toyota Management, Lean Enterprise Institute, Cambridge.

Spear, S. (2005), "Fixing health care from the inside, today", Harvard Business Review, Vol. 83 No. 9 , pp. 78-91.

Spear, S. J. (2006), "Fixing healthcare from the inside: Teaching residents to heal broken delivery processes as they heal sick patients", Academic Medicine, Vol. 81 No. 10, pp. 144-149.

Sugimori, Y., Kusunoki, K., Cho, F., and Uchikawa, S. (1977), "Toyota production system and kanban system materialization of just-in-time and respect-for-human system", International Journal of Production Research, Vol. 15 No. 6, pp. 553-564.

Timmermans, S. and Berg, M. (2003), The Gold Standard: The Challenge of Evidence-based Medicine and Standardization in Health Care, Temple University Press.

Toyota (2001), "The Toyota Way, internal document", Toyota City, Nagoya. 
Tucker, A. and Edmondson, A. (2003), "Why hospitals don't learn from failures: Organizational and psychological dynamics that inhibit system change", California Management Review, Vol. 45 No. 2, pp. 55-72.

Whitson, D. (1997), "Applying just-in-time systems in health care", IIE Solutions, Vol. 29 No. 8, pp. 32-37.

Womack, J. and Jones, D. (1996), Lean Thinking: Banish Waste and Create Wealth in Your Corporation, Simon \& Schuster, New York.

Womack, J., Jones, D., and Roos, D. (1990), The Machine That Changed the World: The Story of Lean Production, Rawson Associates, New York.

Xiao, Y., Schenkel, S., Faraj, S., Mackenzie, C., and Moss, J. (2007), "What whiteboards in a trauma center operating suite can teach us about emergency department communication", Annals of Emergency Medicine, Vol. 50 No. 4, pp. 387-395.

Yin, R. K. (2003), Applications of Case Study Research, Sage Publications, Inc, Thousand Oaks. 